\title{
Early responses to COVID-19 in Afghanistan
}

Shugufa Basij-Rasikh, ${ }^{1}$ Merette Khalil ${ }^{2}$ and Najibullah Safi ${ }^{1}$

${ }^{2}$ World Health Organization Country Office, Kabul, Afghanistan. ${ }^{2}$ World Health Organization Regional Office for the Eastern Mediterranean, Cairo, Egypt. (Correspondence to: Merette Khalil: merette.ramses@gmail.com).

Citation: Basij-Rasikh S; Khalil M; Safi N. Early responses to COVID-19 in Afghanistan. East Mediterr Health J. 2020;26(12):1442-1445. https://doi. org/10.26719/emhj.20.137

Received: 09/07/20; accepted: 29/10/20

Copyright $($ C World Health Organization (WHO) 2020. Open Access. Some rights reserved. This work is available under the CC BY-NC-SA 3.0 IGO license (https://creativecommons.org/licenses/by-nc-sa/3.o/igo).

\section{Introduction}

The World Health Organization (WHO) declared COVID-19 as a pandemic on 13 March 2020. It has spread to more than 200 countries, with over 35 million cases and 1 million deaths, with no guaranteed treatment but recommended preventive measures like hand hygiene and social distancing (1). As a donor-dependent conflict-affected country, Afghanistan faces challenges with health-care delivery and managing its double burden of diseases, given the limited health literacy and preventative measures, shortages of skilled health workers, and fragile health infrastructure $(2,3)$. Afghanistan has a population of 32 million; $75 \%$ live in the rural areas and $80 \%$ living below the poverty line (4). Given Afghanistan's close proximity to China, the Afghan Ministry of Public Health (MoPH) began discussing preparedness measures for COVID-19 as early as December 2019 and predicted that $80 \%$ of the population could be infected with upward of 125000 deaths in Kabul alone if preventative measures were not followed (5-7).

The first case of COVID-19 in Afghanistan was reported on 22 February 2020, when 150000 nationals returned from the Islamic Republic of Iran to Herat (8). More recently (5 October 2020), there were 39422 confirmed cases, 32879 recovered and 1466 deaths, and increasing $(9,10)$. Kabul and Herat are the most affected parts of the country $(9,11)$. Despite its fragile health system and limited preparedness and surveillance capacities, Afghanistan was among the first countries in the Eastern Mediterranean Region and world to consider multisectoral and proactive preparedness measures in managing the COVID-19 outbreak.

\section{National interventions}

Measures to increase preparedness, detection and response to COVID-19 were issued and implemented at a national scale starting January 2020, prior to the first case being diagnosed in-country. One of the earliest measures included cross-border screenings at points of entry (Figure 1); this was due to the surge of returnees from the Islamic Republic of Iran, which at the time was a hot-spot for COVID-19 cases. Presidential decrees to avoid large crowds and upscale hand-hygiene were issued, and Ministry of Interior Affairs (MoI) banned large gatherings, sporting and entertainment events $(2,12)$. Quarantine and lockdown were implemented throughout the country (Figure 1) $(2,13,14)$. Notably, the political changes in government and new minsters of health disrupted the national response to COVID-19 and resulted in policy modifications, fragmentation and delays in implementation.

In March 2020, the MoPH developed the National Emergency Response Plan for COVID-19, in collaboration with the World Health Organization (WHO) $(13,15)$. The government allocated 8 billion afghanis ${ }^{1}$ (Afs) (0.5\% of GDP) for emergency pandemic response, of which 1.9 billion afghanis (0.1\% of GDP) for urgent health needs (6). The government announced lockdown in three provinces bordering the Islamic Republic of Iran due to surge in cases and all flights were suspended from Kabul (14).

\section{Role of media and communication}

Collaboration with media and religious leaders was essential in assuaging panic in communities, combatting misinformation on the virus' spread, and growing stigma against the overburdened health system. MoPH and Ministry of Communication and Technology Affairs jointly developed a mobile application providing updates on COVID-19 (9). The WHO emergency team launched a media campaign, conducted month-long roundtables, and oriented 55256 community and religious leaders in all 34 provinces (13). Information Education and Communication (IEC) materials were developed from the Islamic perspective (including a fatwa regarding COVID-19 preventive measures), and distributed by Ministry of Religious Affairs and WHO; further materials were prepared for those illiterate or have no access to internet $(9,16,17)$. This was particularly important as the first wave of COVID-19 coincided with numerous religious holidays where large gatherings and close physical contact would have been common and a potential spreader of the infection. Unfortunately, MoPH struggled to control communities' adherence to these preventive measures, especially given the shortages of personal protection equipment (PPE) and the harsh economic conditions facing the country (5).

${ }^{1}$ afghani $=$ US\$ 0.013 (29 October 2020) 


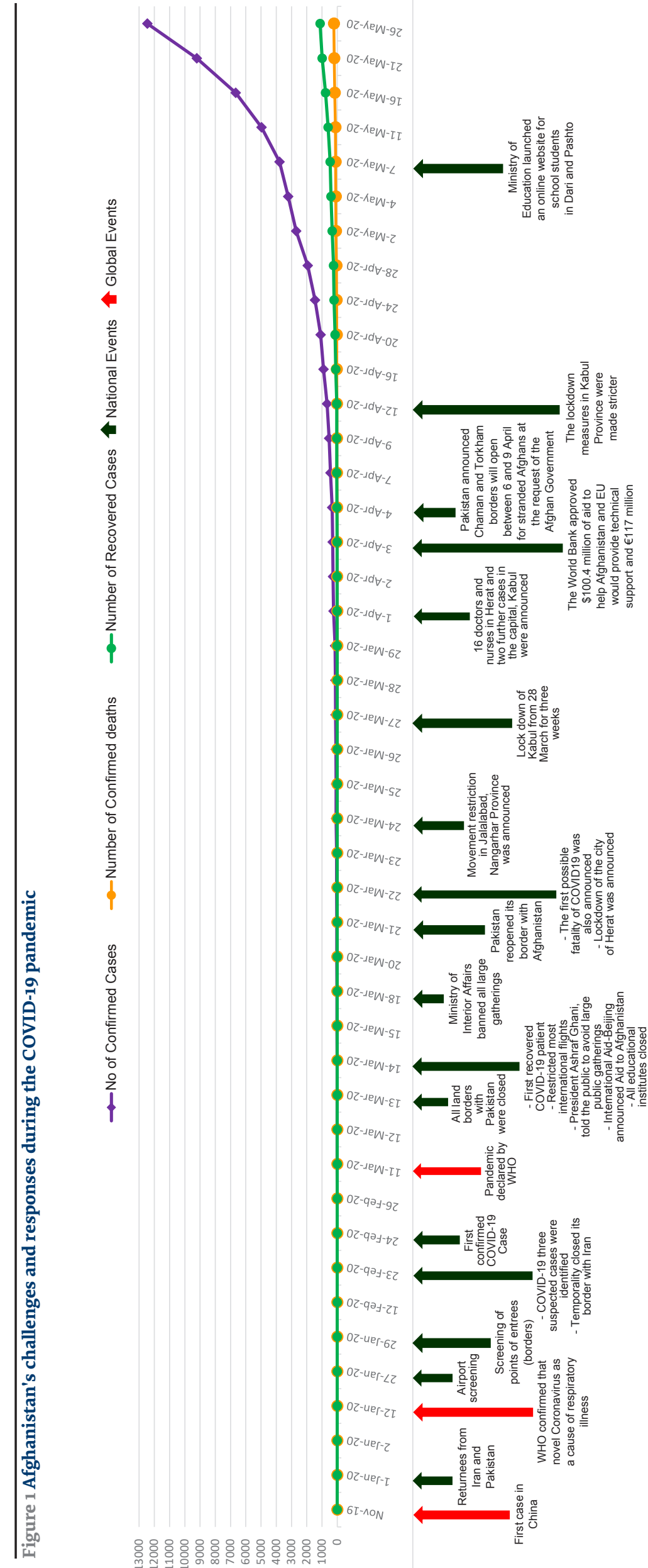




\section{Health systems interventions}

In February 2020, the MoPH designated the Afghan Japan hospital in Kabul as an immediate COVID-19 treatment facility (9). In Afghanistan, 1541 beds are designated for COVID-19 patients, 700 beds in Herat, 200 beds in Kabul, and the remainder are spread around the country $(9,11)$. In Kabul, Darulaman Palace and Kabul and Polytechnic universities' dormitories were converted into isolation facilities. Isolation wards were identified for treatment of patient with COVID-19 in all provinces $(9,11)$. By March 2020, there were 300 ICU beds available for quarantine throughout the country (11).

Regarding service delivery, under the isolation ward protocol, mild and moderate cases were to be quarantined at home to allow severe cases to be monitored at the hospital (18). The role of private hospitals was neither compulsory nor voluntary in COVID-19 response. Given Afghanistan's vertical and contracted-out health systems infrastructure, the provision of non-COVID-19 and essential health services was continued through NGOs, utilizing additional triage and infection prevention and control (IPC) measures (19).

Despite the increasing cases, Afghanistan had one of the lowest national testing capacities in the Region for COVID-19; this challenge was exacerbated by the shortages of testing kits nationally, high costs of testing, insecurity in transporting tests, and the need to export samples abroad for confirmation and verification $(2,5,15)$. By May 2020, there were a total of 9 certified laboratories with the capacity of 1790 tests per day (9). Additionally, Afghanistan decentralized its testing capacity. In addition to the Central Public Health Laboratory (CPHL) (processing 200-300 samples/day) and two veterinary laboratories in Kabul, there were also two laboratories in Herat (150 test/day), one in Nangarhar and one in Paktya, Kandahar, and Balkh provinces, each testing about 100150 COVID-19 cases daily $(2,11,13,16)$.

Despite the limited capacity to confirm and diagnose the virus, Afghanistan stepped up its capacity for identification and contact tracing through utilizing existing surveillance infrastructure. Afghanistan used 520 sentinel sites in all the 34 provinces in both public and private health facilities (11,13). In addition, active surveillance sites have been established in all bordercrossings around the country and involvement of polio workers and rapid response teams (RRTs) used to expand contacttracing,samplecollection, andriskcommunication in insecure areas (16). Regarding equipment, supplies and medicines, United Nations' reports confirmed that due to the reliance on humanitarian and international organizations, Afghanistan had enough PPEs, masks and gloves available in the COVID-19 designated hospitals at the beginning of the response, including approximately 85000 test kits and 600 ventilators throughout the country (9).
There are total of 8996 medical doctors, 12588 nurses and 26696 midwives, resulting in a shortage of skilled health workers nationally, and the issue of maldistribution since the majority are concentrated in urban areas and some $60 \%$ work in public-health facilities (3). To respond to the COVID-19 pandemic, MoPH issued a call to recruit fresh graduates, volunteers, and registered medical professionals to work in designated hospitals. In May 2020, 763 medical staff were trained on IPC and case management $(9,20)$. However, despite some financial incentives (hardship payments), it was difficult to retain many of these staff due to the challenging working conditions, high risk of infection, limited PPE, and inadequate training and experience in managing critical cases (especially for new graduates).

\section{Recommendations to improve the COVID-19 response}

The impact of COVID-19 on health, education and the economy, especially in fragile contexts such as Afghanistan, is difficult to ignore. An evaluation of Afghanistan's experiences in combatting COVID-19 and the lessons learned from responses and interventions in the early months would benefit policy-makers at the national level as well as public health researchers and humanitarian actors in similar settings. While Afghanistan has taken many pro-active measures to prevent the transmission of the disease, further multi-sectoral policies would not only improve the efficiency of the current response but may be proactively established ahead of a second wave (5); these include:

- Increasing budget allocation towards the health-care sector to improve hospital facilities, proper staffing, and procurement of required medical equipment;

- scaling up capacity building of health-care professionals for use of PPE, IPC, rapid detection, case management, and critical care services;

- recruiting additional health workers, and engaging community health workers and community actors in COVID-19 surveillance;

- expanding use of telehealth care and helpline services to support service delivery while maintaining quarantine, particularly to improve access in rural and remote areas;

- continuing health promotion activities, particularly for illiterate and hard-to-reach populations, to raise awareness and increase use of preventive practices such as handwashing and using masks;

- raising awareness to reduce myths and stigma associated with COVID-19, through continued media campaigns and engagement of religious and community leaders;

- focusing on internally displaced populations and returnees to ensure adequate screening, health 
education, and access to health services;

- engaging with the private sector to expand and optimize service delivery, surveillance, laboratory capacity and prevention;

- analyzing the psychological impact of COVID-19 on the population and incorporating therapy and psychological support services in the service delivery plan; and

- conducting scientific research on preventive measures and practices in rural and urban areas to limit the spread of infection.

\section{References}

1. World Health Organization. Coronavirus Disease (COVID-19) Dashboard. Geneva: World Health Organization; 2020 (https://covid19.who.int/).

2. Shah J, Karimzadeh S, Al-Ahdal TMA, Mousavi SH, Zahid SU, Huy NT. COVID-19: the current situation in Afghanistan. The Lancet Global Health. 2020 Apr 2. https://doi.org/10.1016/S2214-109X(20)30124-8

3. Safi N, Naeem A, Khalil M, Anwari P, Gedik G. Addressing health workforce shortages and maldistribution in Afghanistan. East Mediterr Health J. 2018;24(9):951-958. https://doi.org/10.26719/2018.24.9.951.

4. Afghanistan Humanitarian Needs Overview 2020 (December 2019) - Afghanistan. ReliefWeb. (https://reliefweb.int/report/afghanistan/afghanistan-humanitarian-needs-overview-2020-december-2019).

5. Mousavi SH, Abdi M, Zahid SU, Wardak K. Coronavirus disease 2019 (COVID-19) outbreak in Afghanistan: Measures and challenges. Infect Control Hosp Epidemiol. 2020 May 15:1-2.

6. International Monetary Fund (IMF). Policy responses to COVID19 [Internet]. Policy Tracker COVID19. (https://www.imf.org/en/ Topics/imf-and-covid19/Policy-Responses-to-COVID-19).

7. United States Embassy. COVID Information. Kabul: United States Embassy; 2020 (https://af.usembassy.gov/covid-19-information/\%3E).

8. Azizy A, Fayaz M, Agirbasli M. Do not forget Afghanistan in times of COVID-19: Telemedicine and the internet of things to strengthen planetary health systems. OMICS: A Journal of Integrative Biology. 2020:Apr 23 (https://www.liebertpub.com/doi/ full/10.1089/OMI.2020.0053).

9. World Health Organization. Coronavirus disease 2019 (COVID-19) Weekly Situation Report No. 15;5. Kabul: World Health Organization; 2020.

10. World Health Organization Regional Office for the Eastern Mediterranean (WHO/EMRO). COVID-19 Dashboard. Cairo: WHO/ EMRO: 2020 (https://app.powerbi.com/view?r=eyJrIjoiN2ExNWI3ZGQtZDk3MyooYzE2LWFjYmQtNGMwZjkoOWQ1MjFhIiwidCI6ImY2MTBjMGI3LWJkMjQtNGIzOSo4MTBiLTNkYzI4MGFmYjU5MCIsImMiOjh9).

11. United Nations Development Programme (UNDP). Afghanistan's support to national response Geneva: UNDP; 2020 (https:// www.af.undp.org/content/afghanistan/en/home/coronavirus/support-to-national-response.html).

12. Ahelbarra H. Afghans brace for COVID-19 outbreak. Aljazeera online, April 2020 (https://www.aljazeera.com/news/2020/04/afghans-brace-covid-19-outbreak-200415055726150.html).

13. Afghanistan Ministry of Public Health (MoPH). Covid-19 emergency response and health system preparedness directorate. Kabul: MoPH; 2020 (https://moph.gov.af/en/covid-19-pandemic).

14. Afghanistan Ministry of Public Health (MoPH). Afghanistan COVID-19 emergency response. P173775: environmental and social commitment plan (ESCP). Kabul: MoPH; 2020.

15. Wardak M. The COVID19 reality of Afghanistan. Observer Research Foundation. 2020 (https://www.orfonline.org/expert-speak/ the-covid-19-reality-of-afghanistan-64847/).

16. United Nations Office for the Coordination of Humanitarian Affairs (UNOCHA). Afghanistan Flash Update: Daily Brief: COVID-19, No. 16 (20 March 2020) - Afghanistan (https://reliefweb.int/report/afghanistan/afghanistan-flash-update-daily-brief-covid19-no-16-20-march-2020).

17. United Nations Office for the Coordination of Humanitarian Affairs (UNOCHA). Afghanistan Flash Update: Daily Brief: COVID-19, No. 40 (30 April 2020) - Afghanistan (https://reliefweb.int/report/afghanistan/afghanistan-flash-update-daily-brief-covid19-no-40-30-april-2020).

18. Afghanistan Ministry of Public Health (MoPH). Measures and actions taken by the Ministry of Public Health to prevent and control the spread of the new coronavirus in Afghanistan. Kabul: MoPH; 2020 (https://moph.gov.af/dr/).

19. Integrated package of essential health services for Afghanistan. London: London School of Hygiene and Tropical Medicine; 2020 (https://www.lshtm.ac.uk/newsevents/news/2019/integrated-package-essential-health-services-afghanistan).

20. United Nations Office for the Coordination of Humanitarian Affairs (UNOCHA). Afghanistan: COVID-19 multi-sectoral response operational situation report, 20 May 2020 - Afghanistan (https://reliefweb.int/report/afghanistan/afghanistan-covid-19-multi-sectoral-response-operational-situation-report-20-may). 